\title{
O éthos e o páthos na publicidade da Dove: uma construção sincrética
}

\author{
Ethos and pathos on Dove's publicity: a syncretic construction
}

El éthos y el páthos en la publicidad de Dove: una construcción sincrética

Roseméri Lorenz ${ }^{1}$

Luciana Maria Crestani $\oplus^{1}$

${ }^{1}$ Universidade de Passo Fundo, Passo Fundo, RS, Brasil.

\author{
$\diamond$
}

\begin{abstract}
RESUMO
Objeto de pesquisa desde a antiguidade clássica - na Retórica, de Aristóteles -, muitas são as teorias que, ainda hoje, sobre a construção do éthos e do páthos se debruçam, entre elas a semiótica greimasiana, aqui adotada. A partir de seus pressupostos, este estudo busca investigar que éthos e que páthos emergem da relação entre verbal e não verbal no discurso publicitário da marca de produtos de higiene e beleza Dove. Para isso, procede à análise de dois anúncios impressos, produzidos, respectivamente, em 2005 e 2016. Por meio do exame das marcas da enunciação recorrentes na superfície textual, manifestadas no seu plano de conteúdo e no de expressão, pretende-se, de modo mais específico, identificar que mecanismos atuam, bem como descrever a sua atuação, no processo de produção dessas imagens do enunciador e do enunciatário.
\end{abstract}

Palavras-chave: Éthos. Páthos. Sincretismo. Plano de conteúdo. Plano de expressão.

\begin{abstract}
A research object from classical antiquity - in Aristotle's Rhetoric - many are the theories that still apply on the construction of ethos and pathos, among them the greimasian semiotics, adopted here. Based on its assumptions, this study seeks to investigate which ethos and pathos emerge from the relationship between verbal and nonverbal in the advertising discourse of the Dove brand of hygiene and beauty products. To do this, it analyzes two print ads, produced in 2005 and 2016, respectively. In examining the recurrent marks of enunciation on the textual surface, expressed in its content and expression plans, it is intended to identify which mechanisms act in a more specific way, as well as to describe their performance in the process of producing these images of enunciate and enunciator.
\end{abstract}

Keywords: Ethos. Pathos. Syncretism. Content plan. Expression plan.

\section{RESUMEN}

Objeto de investigación desde la antigüedad clásica - en la Retórica, de Aristóteles -, muchas son las teorías que, aún hoy, sobre la construcción del éthos y del páthos se encargan, entre ellas la semiótica greimasiana, aquí adoptada. Desde sus supuestos, este estudio busca investigar qué éthos y qué páthos emergen de la relación entre verbal y no verbal en el discurso publicitario de la marca de productos de higiene y belleza Dove. Así, procede el análisis de dos anuncios impresos, producidos, respectivamente, en 2005 y 2016. A través del examen de las marcas de la enunciación recurrentes en la superficie textual, manifestadas en su plan de contenido y en el plan de expresión, se desea, de modo más específico, identificar qué mecanismos actúan, así como describir su actuación, en el proceso de producción de esas imágenes del enunciador y del enunciatario.

Palabras clave: Éthos. Páthos. Sincretismo. Plan de contenido. Plan de expresión. 


\section{Introdução}

Não há dúvidas de que a publicidade vende mais do que produtos, vende ideias. Para isso, o enunciador pressupõe uma imagem do enunciatário (páthos) a quem o discurso (lógos) deve persuadir. Assim, por meio de suas escolhas enunciativas, verbais e não verbais, o enunciador projeta no enunciado os valores que imagina que sejam aspirados pelo enunciatário e, correspondentemente, os vinculados à sua própria imagem (éthos). Essa curiosa construção de identidades tem sido objeto de estudo de diversas teorias linguísticas ao longo dos anos, entre elas a semiótica greimasiana, a qual fundamenta este estudo. A opção por tal linha teórica justifica-se por ela se dedicar à questão da organização dos sentidos, buscando explicarlhe a construção a partir dos elementos mais superficiais do texto até chegar a suas instâncias mais profundas. Tais características se integram perfeitamente às necessidades analíticas do tema em questão, uma vez que o éthos e o páthos emergem justamente de marcas da enunciação, recorrentes na superfície textual, e se constituem, no caso dos textos publicitários, de modo sincrético, explicitandose tanto na linguagem verbal quanto na não verbal.

Considerando isso, o presente artigo busca analisar que éthos e que páthos são construídos, por meio da correlação entre recursos verbais e não verbais, no discurso publicitário da marca de produtos de higiene e beleza Dove. O interesse inicial por esse objeto de análise surgiu a partir do conhecimento das significativas alterações efetuadas pela marca em suas criações publicitárias a partir de 2004, quando pesquisa de alcance mundial constatou que a maioria das mulheres não se via representada nos anúncios de cosméticos, os quais, historicamente, (re) produziam um padrão estético ideal. Esses resultados determinaram o surgimento da campanha "Real Beleza", a partir da qual a marca substitui as modelos profissionais por "mulheres comuns", propondo a aceitação do corpo com suas características "reais". A iniciativa foi tão bem sucedida que determinou um substancial aumento das vendas dos produtos da marca em todo o mundo. Diante desse contexto, julgou-se pertinente investigar como enunciador e enunciatário constroem mutuamente suas imagens pela enunciação, imagens essas que servem de coerções na produção discursiva e atuam como forma de identificação entre empresa e cliente, contribuindo para adesão de determinado público ao discurso. Nesse sentido, pretende-se aqui, mais especificamente, determinar que mecanismos atuam, bem como descrever sua atuação, no processo de produção de imagens enunciativas projetadas nos anúncio. É importante ressaltar que tal investigação também pode representar uma contribuição social, uma vez que a discussão sobre os recursos linguísticos empregados na produção de tais discursos potencializa o debate acerca das imposições estéticas da sociedade, propiciando seu enfrentamento, bem como auxiliando na aceitação social da diversidade.

Assim, tendo em vista atingir os objetivos propostos e desenvolver o tema de modo ordenado, primeiramente se procurará demonstrar como a semiótica concebe a enunciação dentro de seu modelo de produção do sentido. Após, serão expostas algumas considerações sobre o sincretismo de linguagens, focalizando especialmente o gênero publicitário. Na seção seguinte, as noções de éthos e páthos serão brevemente apresentadas. Em seguida, serão descritos os procedimentos metodológicos utilizados neste estudo e, finalmente, efetuada a análise do corpus selecionado.

\section{Enunciação e semiótica}

Não há como abordar a enunciação sem se reportar à Émile Benveniste (1995, p. 80), segundo o qual, ao se enunciar como "eu", e apropriar-se do sistema, o locutor constitui-se como sujeito no e do discurso, instaurando um "tu" a quem se dirige e, ao mesmo tempo, tornandose ponto de referência para a instauração de um espaço e de um tempo. Seguindo essa concepção benvenisteana, a semiótica francesa considera a enunciação como uma "[...] instância de mediação, que assegura a colocação em enunciado-discurso das virtualidades da língua" (GREIMAS; COURTÉS, 2013, p.166). Ou seja, com a enunciação, ocorre a passagem da língua ao discurso, passagem esta realizada, principalmente, por meio das categorias de pessoa, espaço e tempo (ego, hic et nunc). Assim, tendo como objeto de estudo o discurso, manifestado pelo texto, o qual é a união de um plano de conteúdo com um plano de expressão (verbal, não verbal ou sincrético), a semiótica busca compreender e explicar todas as escolhas enunciativas (conscientes ou inconscientes) que visem à produção de efeitos de sentido.

Antes de se descrever tais procedimentos discursivos, entretanto, torna-se necessário entender como a semiótica concebe a construção de sentidos. Para isso, é conveniente fazer uma breve incursão ao modelo de produção do sentido, proposto por Greimas, denominado percurso gerativo de sentido, o qual apresenta diferentes graus de abstração e se estabelece em três níveis: o fundamental, o narrativo e o discursivo. Cada um desses níveis possui uma sintaxe (combinação de mecanismos que ordena os conteúdos) e uma semântica (conteúdos investidos nos arranjos sintáticos).

O primeiro patamar do percurso gerativo é o das estruturas fundamentais, onde surgem os significados mais simples e abstratos (GREIMAS; COURTÉS, 2013, p.436). A semântica desse nível organiza-se a partir da oposição de dois termos pertencentes à mesma categoria 
semântica como, por exemplo, vida versus morte, comum versus incomum, naturalidade versus artificialidade. Por sua vez, a sintaxe do nível fundamental estabelece um percurso entre os termos da categoria semântica, os quais se organizam a partir de operações de negação e asserção.

No nível narrativo, os termos das oposições semânticas fundamentais são assumidos por sujeitos, cujas ações desencadeiam mudanças de estado. A sintaxe narrativa trata, justamente, dessas mudanças de estado dos sujeitos em relação a determinados objetos. Por sua vez, a semântica narrativa dedica-se aos valores inscritos nos objetos. Não se irá aqui, entretanto, pormenorizar a constituição desse nível, uma vez que não se revela pertinente aos objetivos deste estudo.

Aúltima etapa do percurso gerativo é onível discursivo, que constitui o patamar mais superficial, o mais próximo da manifestação textual. A sintaxe discursiva busca analisar as relações enunciador-enunciado (projeções do enunciador no enunciado por meio das categorias de pessoa, tempo e espaço) e enunciador-enunciatário. Já em sua organização semântica, os percursos narrativos são convertidos em percursos temáticos, os quais podem ou não ser cobertos por figuras.

A começar pelas relações entre enunciador e enunciado, verificam-se dois processos de instauração de pessoas, espaços e tempos no enunciado: a debreagem e a embreagem.

A debreagem é definida por Greimas e Courtés (2013, p.111) como a projeção das categorias de pessoa, de tempo e de espaço da enunciação no enunciado. De acordo com os autores (2013, p.112), quando se instalam no enunciado os actantes da enunciação, "eu/ tu", no espaço do "aqui" e no tempo do "agora", ocorrem debreagens enunciativas. Se, no entanto, for instaurado o actante do enunciado, "ele", no espaço do "lá" e no tempo do "então", ocorrem debreagens enuncivas.

Os dois tipos de discurso resultantes de tais projeções produzem diferentes efeitos de sentido. Os projetados em primeira pessoa (enunciação enunciada), por simularem a enunciação, acabam aproximando-se dela, criando efeitos de subjetividade, de parcialidade. Já os projetados em terceira pessoa (enunciado enunciado), por se distanciarem da enunciação, produzem efeitos de objetividade, de imparcialidade.

É preciso ressaltar que essas projeções também se evidenciam visualmente. Conforme Barros (2012, p. 40): "Há gestos 'em primeira pessoa' e gestos 'em terceira pessoa', e a gestualidade estabelece também o contexto temporal e espacial da situação de comunicação". Em um anúncio publicitário, por exemplo, o olhar do ator ou seus gestos com a mão e a cabeça, dirigidos ao destinatárioleitor, constituem uma enunciação enunciada. Se, ao contrário, tais sinais não se dirigem a ele, mas a outros atores do enunciado, há um enunciado enunciado. Os efeitos de sentido produzidos são os mesmos da comunicação verbal.

Há, ainda, as debreagens internas (de segundo grau), que introduzem interlocutores, em discurso direto, criando um efeito de realidade, pois produzem a ilusão de diálogo real.

Além dos efeitos enunciativos produzidos pelas modalidades de debreagem, há os obtidos pelo procedimento inverso: a embreagem. Segundo Greimas e Courtés (2013, p. 159-160), “[...] denomina-se embreagem o efeito de retorno à enunciação, produzido pela suspensão da oposição entre certos termos da categoria de pessoa e/ ou do espaço, e/ou do tempo, bem como pela denegação da instância do enunciado". Tal recurso é frequentemente utilizado no cotidiano. Se um professor, por exemplo, ao repreender seus alunos, diz "O professor não os autorizou a sair da sala", está neutralizando a oposição "eu"/ "tu", empregando a terceira pessoa no lugar da primeira. Nesse caso, o enunciador nega toda subjetividade, reforçando seu papel social, o que produz um efeito de autoridade.

Ainda na sintaxe discursiva, é preciso considerar, também, as relações argumentativas entre enunciador e enunciatário. $\mathrm{O}$ enunciador é o responsável pela persuasão, enquanto o enunciatário, pela interpretação. Entre eles se estabelece um contrato de veridicção pelo qual o enunciador determina, através de marcas deixadas no enunciado, como o discurso deve ser lido pelo enunciatário. Este, por sua vez, precisa encontrar as pistas, relacioná-las a seus conhecimentos e convicções para, assim, acreditar ou não no discurso. Barros (1997, p.64) acrescenta que "[...] o enunciador não produz discursos verdadeiros ou falsos, mas fabrica discursos que criam efeitos de verdade ou de falsidade, que parecem verdadeiros ou falsos e como tais são interpretados". Daí a importância do estudo dos procedimentos discursivos empregados pelo enunciador para construir tais "ilusões".

Além dos procedimentos da sintaxe discursiva, já expostos, a "fabricação" desses e de outros efeitos de sentido resultam também de mecanismos da semântica discursiva. Nela, as estruturas narrativas são convertidas em percursos temáticos que, por sua vez, são cobertos, ou não, por figuras. As figuras constituem a representação, a concretização, do mundo, real ou fictício. Já os temas são elementos abstratos que organizam, classificam, ordenam a realidade. Constituindo "escolhas" enunciativas, figuras e temas disseminados no discurso acabam imprimindo nele, mesmo inconscientemente, as concepções do enunciador. Nas palavras de Barros (2004, p. 12): "Os temas e as figuras são determinados sócio-historicamente e trazem para os discursos o modo de ver e de pensar o mundo de classes, grupos e camadas sociais, garantindo assim o caráter ideológico desses discursos". 
De acordo com a autora (2004, p. 14), nos textos predominantemente temáticos, as figuras esparsas (história, imagem, fotografia) contribuem no processo de persuasão do enunciatário, pois, ao servirem como exemplo, modelo, ilustração, ou outra estratégia de argumentação, produzem efeitos de realidade/ irrealidade, verdade/falsidade, levando o enunciatário a crer e a fazer. No caso dos textos predominantemente figurativos, a figurativização constrói diversos efeitos de sentido. Quando elevado a um grau extremo (iconização), cria um efeito de realidade, levando o enunciatário a reconhecer figuras do mundo e interpretá-las como reais. É o que ocorre na fotografia, ou na pintura figurativa, por exemplo. A figurativização também pode produzir um efeito de concretização sensorial, dando "corporalidade" ao discurso e às relações entre enunciador e enunciatário. Nesse caso, como afirma Barros (2004, p. 13), "os temas abstratos são 'recobertos' por traços semânticos 'sensoriais' de cor, de forma, de cheiro, de sons, etc.". Há ainda os efeitos de novidade, de criatividade, os quais proporcionam prazer estético, construídos por meio de relações inusitadas, que se distanciam do senso comum, entre o figurativo e o temático, ou pela combinação de figuras de modo diferenciado.

Para se depreender adequadamente todos os efeitos de sentido advindos das projeções enunciativas, devemse considerar as relações entre as múltiplas linguagens empregadas pelo enunciador para constituir um todo significativo. Sendo assim, a essas relações que se dedicará a próxima seção.

\section{Sincretismo de linguagens na publicidade}

O texto publicitário, em geral, articula diversas linguagens na construção de seus sentidos (no caso de anúncios impressos, como os que serão analisados neste estudo, a articulação ocorre entre a verbal e a visual), o que o define como um texto sincrético.

É preciso considerar que a semiótica greimasiana concebe dois conceitos de sincretismo. O primeiro deles, inspirado nos estudos de Hjelmslev sobre fonologia, diz respeito à superposição de categorias englobadas por uma mesma grandeza. O fenômeno fonológico da neutralização, por exemplo, quando dois fonemas diferentes perdem a função distintiva constitui, para Hjelmslev, um caso de sincretismo (é a situação dos fonemas vocálicos /e/ e /i/, distintivos em vela/ vila, mas não distintivos em posição átona final, como em lequ[e] e lequ[i]). Essa concepção é transposta por Greimas e Courtés (2013, p.467) para as categorias do texto. Assim, segundo os autores, quando, no nível narrativo, o sujeito de estado é, simultaneamente, sujeito do fazer, ocorre a superposição de duas categorias de uma mesma grandeza.

Essa noção de superposição é posteriormente ampliada, passando a referir-se ao que tais autores denominam "semióticas sincréticas", que "acionam várias linguagens de manifestação" (GREIMAS; COURTÉS, 2013, p.467). Devido à imprecisão desse segundo conceito, muitos estudiosos não identificaram nele a base hjelmsleviana. Entretanto, Fiorin (2009, p. 38) esclarece que não há uma enunciação para cada linguagem, o que resultaria em uma mera justaposição de linguagens, sem superposição da forma de expressão. Ao contrário, há um mesmo enunciador, que produz uma enunciação sincrética única, empregando várias linguagens de manifestação, tendo em vista produzir um todo de sentido. Por isso, o autor afirma: "Melhor que falar em semióticas sincréticas seria dizer textos sincréticos" (FIORIN, 2009, p. 38).

É preciso considerar que, para se captar adequadamente o sentido global dos textos sincréticos é imprescindível observar as estratégias enunciativas que articulam a relação entre as linguagens e que se manifestam tanto no plano de conteúdo, como no de expressão. No que se refere ao conteúdo, segundo Teixeira (2004, p.235), essa relação pode ser contratual ou polêmica. No primeiro caso, as várias linguagens buscam reiterar uma mesma perspectiva. Já no segundo, elas apresentam perspectivas opostas, conflitantes. Deve-se frisar, contudo que em ambos os casos "[...] uma enunciação única confere ao arranjo das partes e às múltiplas manifestações de linguagem um caráter de unidade" (TEIXEIRA, 2004, p. 236).

Segundo Gomes (2009, p.218-220), as relações entre as linguagens podem apresentar-se de forma heterogênea em cada texto. Para a autora, quando o vínculo entre as linguagens for contratual, pode ocorrer um redimensionamento ou uma ressignificação. O redimensionamento realiza-se por complementação, quando uma linguagem amplia o sentido da outra; ou por restrição, quando uma linguagem limita a outra. A ressignificação, por sua vez, diz respeito à transformação de conteúdos, isto é, quando uma linguagem ressignifica a outra, instaurando metáforas ou metonímias. No caso do vínculo polêmico, a autora salienta que a articulação entre as linguagens pode criar enunciados antitéticos ou paradoxais que, no entanto, organizam-se em um todo coerente. Também se pode, por meio da oposição de pontos de vista, construir ironias ou produzir humor. "É importante ressaltar que, qualquer que seja o procedimento de sincretização do conteúdo, mesmo que surja a oposição como categoria que explica a correlação entre linguagens, há sempre uma base isotópica que a sustenta" (GOMES, 2009, p.220).

Além do plano de conteúdo, revela-se de fundamental importância examinar o plano de expressão de textos com 
função estética (poemas, pinturas etc.), ou seja, aqueles em que o referido plano não se limita a veicular o conteúdo (textos utilitários), mas contribui para seu sentido global. No que tange particularmente ao texto publicitário, podese dizer que ele apresenta tanto função utilitária, pois busca persuadir o enunciatário a adquirir determinado produto ou a agir de certo modo, como estética, já que, para tal processo de convencimento, emprega inúmeros recursos expressivos.

Entretanto, é preciso considerar que o estudo do plano de expressão não tem uma sistematização tão bem definida como a do plano de conteúdo. No caso dos textos visuais, isso se deve, em parte, a dificuldades metodológicas provenientes de particularidades dos objetos de estudo, que, de certa forma, inviabilizam a criação de categorias fixas e universais. Uma escultura, por exemplo, não pode ser estudada sob os mesmos critérios de uma pintura, uma vez que empregam elementos expressivos distintos. Dessa forma, qualquer análise do plano de expressão visual deve levar em conta as particularidades de manifestação de cada texto.

Apesar disso, Greimas (2004, p. 85) sugere uma segmentação das imagens realizada "[...] pela sua decomposição em partes menores e pela reintegração das partes nas totalidades que constituem". A fim de operacionalizar tal processo, o autor propõe o isolamento de contrastes plásticos, de acordo com as dimensões presentes no plano de expressão de cada texto. Tais dimensões seriam: eidética (relativa à forma, como "retilíneo versus curvilíneo", "horizontal versus vertical", "grande versus pequeno"); fotológica (relacionada à luz, como "claro versus escuro", "brilhante versus opaco".); cromática (nível da cor, como "primária versus secundária", "quente versus fria", "preto versus branco"); topológica (referente à espacialidade, como "central versus periférico"; "alto versus baixo"; "direita versus esquerda").

Tais oposições do plano de expressão podem relacionar-se diretamente às presentes no plano do conteúdo. Surge, então, o conceito de semissimbolismo, apresentado, inicialmente, por Greimas e Courtés (2013, p. 454) e, posteriormente, desenvolvido de forma mais ampla por Jean-Marie Floch, que o aplicou a textos de diferentes gêneros, como pintura, fotografia, anúncios publicitários, histórias em quadrinhos.

O semissimbolismo constitui, pois, uma correlação entre categorias do plano de conteúdo e de expressão, como demonstra Monteiro (2005, p.45), tomando-se como exemplo a bandeira nacional. Nela, os elementos concretos (figuras), "matas" e "céu", são representados por cores mais escuras, enquanto os abstratos (temas), "riqueza" e "paz", por cores mais claras. Tem-se, assim, um semissimbolismo entre a categoria "concretude versus abstração", do plano de conteúdo, e a categoria "escuro versus claro", do plano de expressão.

Tanto os procedimentos do plano de conteúdo como os do plano de expressão, aqui pormenorizados, atuam na construção do éthos e do páthos. Esse é o assunto a ser discutido na próxima seção.

\section{0 éthos e o páthos}

Ao tomar a palavra, o enunciador, de modo voluntário ou não, acaba construindo no discurso uma imagem de si, um éthos. Da mesma forma, ao produzir o discurso, o enunciador efetua suas escolhas enunciativas a partir da imagem que tem do enunciatário, isto é, o páthos. Para se compreender com maior clareza esse fenômeno, é necessário recorrer à Retórica, de Aristóteles (2008, I, p. 1356a), para o qual as "provas de persuasão, fornecidas pelo discurso, são de três espécies: umas residem no caráter moral do orador [o éthos]; outras, no modo como se dispõe o ouvinte [o páthos]; e outras, no próprio discurso [o lógos]".

Em especial sobre o éthos, o filósofo grego salienta que tal imagem resulta de uma apreensão do sujeito construído pelo discurso, não de uma mera impressão subjetiva (ARISTÓTELES, 2008, I, p.1356a). Dessa forma, segundo Aristóteles, para construir uma imagem positiva de si, o enunciador deve recorrer a três qualidades: a prudência (phrónesis), a virtude (areté) e a benevolência (eúnoia). A primeira refere-se à ponderação, ao bom senso, à sabedoria com que se exprime o orador. A segunda apresenta-se pela franqueza, sinceridade e simplicidade por ele manifestadas. Já a terceira diz respeito ao caráter agradável e gentil do orador para com o auditório (ARISTÓTELES, 2008, II, p. 1378a).

Após Aristóteles, a retórica constituiu base para inúmeros estudos referentes à imagem do locutor, entretanto o termo éthos só foi inserido nos estudos linguísticos por Oswald Ducrot, em sua teoria polifônica da enunciação. Nela, o autor apresenta uma distinção entre o "locutor-L" (enunciador) e "locutor-lambda" (ser do mundo). $\mathrm{O}$ éthos, segundo o autor está associado ao "locutor-L", ou seja, mostra-se na enunciação, não no enunciado (DUCROT, 1984, p. 201). Em outras palavras, o éthos é percebido não por aquilo que o locutor diz de si mesmo no discurso, mas por aquilo que nele deixa transparecer por meio, por exemplo, da entonação, das escolhas lexicais, dos argumentos.

Maingueneau (2008, p. 17) também se apoia na Retórica para construir sua noção de éthos, inclusive ampliando-a para abranger não só os textos orais, mas também os escritos. Para ele, o éthos apresenta três componentes: o caráter (conjunto de traços psicológicos que o enunciatário atribui ao enunciador devido a seu 
discurso); o corpo (representação da constituição física do enunciador); o tom (a voz que permite ao enunciatário formar a imagem do enunciador). Assim, a noção de éthos

[...] recobre não somente a dimensão vocal, mas também o conjunto de determinações físicas e psíquicas atribuídas pelas representações coletivas à personagem do orador. O "fiador", cuja figura o leitor deve construir com base em indícios textuais de diversas ordens, vê-se, assim, investido de um caráter e de uma corporalidade, cujo grau de precisão varia conforme os textos (MAINGUENEAU, 2013, p. 72).

No que concerne à construção do éthos por meio de indícios textuais, aliás, as perspectivas de Ducrot e Maingueneau apresentam afinidade à da semiótica de Greimas. Embora sem fazer menção ao termo, o linguista lituano concebe a noção de narrador digno de confiança ao tratar, no nível narrativo, do chamado "contrato fiduciário". Tal contrato pode basear-se em uma evidência, ou ser antecedido por um fazer persuasivo (fazer-crer) do destinador-manipulador que corresponde a um fazer interpretativo do sujeito. No nível discursivo, esse contrato transforma-se em contrato veridictório pelo qual, como já se demonstrou, o enunciador "semeia" pistas no enunciado, determinando o modo como o discurso deve ser lido pelo enunciatário. Este, por sua vez, ao analisar as pistas pode, ou não, acreditar na verdade (ou falsidade) do discurso (GREIMAS; COURTÉS, 2013, p. 101).

Fiorin $(2008$, p. 141) salienta que o éthos pode manifestar-se em diferentes níveis enunciativos: enunciador, narrador, interlocutor. Este se torna de fácil identificação, uma vez que remete às características físicas e psicológicas de uma dada personagem da obra. Já a determinação da imagem do enunciador e a do narrador tem a ver com a totalidade ou parcialidade da obra de um autor. Pela análise de apenas uma obra, pode-se determinar o éthos do narrador. Ao se analisar o conjunto das obras, define-se o éthos do enunciador.

De forma mais específica, para a depreensão do éthos do enunciador é necessário procurar

[...] as recorrências em qualquer elemento composicional do discurso ou do texto: na escolha do assunto, na construção das personagens, nos gêneros escolhidos, no nível de linguagem usado, no ritmo, na figurativização, na escolha dos temas, nas isotopias, etc (FIORIN, 2008, p. 143).

Por sua vez, no que diz respeito ao páthos, Aristóteles afirma: "Persuade-se pela disposição dos ouvintes, quando estes são levados a sentir emoção por meio do discurso, pois os juízos que emitimos variam conforme sentimos tristeza ou alegria, amor ou ódio" (2008, I, p. 1356a).
Assim, convencer o enunciatário requer conhecê-lo. Mas, Fiorin (2008, p. 154) esclarece que, quando se trata do páthos não se está fazendo referência à disposição real do enunciatário, mas sim à imagem deste construída pelo enunciador. É essa imagem que determina as escolhas enunciativas, conscientes ou inconscientes, do enunciador ao construir o enunciado. "Por outro lado, o enunciatário adere ao discurso, porque nele se vê constituído como sujeito, identificando-se com o éthos do enunciador" (FIORIN, 2008, p. 157). Dessa forma, o discurso tornase eficaz quando o enunciatário assimila o éthos do enunciador. Isso pode ocorrer de modo harmônico (éthos e páthos em sintonia), ou complementar (éthos supre uma necessidade do páthos).

Da mesma forma como ocorre com o éthos, o páthos também pode ser determinado em diversas instâncias enunciativas. Considerando-se um único texto, pode-se identificar a imagem do narratário, já em um conjunto deles é possível construir a imagem do enunciatário. Isso ficará evidente nas análises que seguem.

\section{Procedimentos metodológicos}

Após a exposição teórica, torna-se necessário apresentar os princípios metodológicos que irão guiar o exame dos textos que compõem o corpus.

Tal exame tem como base as diretrizes da teoria semiótica, preconizadas por Greimas (2013), segundo as quais se deve, em uma primeira etapa de análise, promover uma abstração da manifestação - seja verbal, visual, sincrética - a fim de examinar o plano de conteúdo, deixando para um segundo momento o estudo das especificidades da expressão, bem como sua relação com o conteúdo.

No que se refere particularmente à análise do plano de conteúdo, é necessário lembrar que a referida teoria defende a adoção de um modelo de produção do sentido - o percurso gerativo de sentido - formado pelos níveis fundamental, narrativo e discursivo. Como se pretende aqui analisar o éthos e o páthos de anúncios publicitários, depreendidos por meio das marcas linguísticas e imagéticas presentes no enunciado, os anúncios selecionados como corpus serão examinados do ponto de vista do leitor, ou seja, neles serão identificados, primeiramente, os elementos mais superficiais, presentes em seu nível discursivo, a fim de chegar à sua instância mais profunda, isto é, ao nível fundamental.

O corpus do estudo é formado por dois anúncios publicitários impressos da marca Dove.

Considerando que o objetivo deste estudo é analisar, fundamentado teoricamente na semiótica discursiva, que éthos e que páthos são construídos (e como são construídos), por meio da correlação entre recursos 
verbais e visuais, no discurso publicitário da Dove, procurar-se-á seguir as seguintes etapas:

a) identificar as marcas (verbais e não verbais) da enunciação que constituam indícios das projeções do enunciador como narrador e do enunciatário como narratário;

b) buscar os efeitos de sentido decorrentes de tais projeções, os quais contribuam para a construção do éthos do narrador e do páthos do narratário;

c) identificar, em cada texto, os investimentos temáticos e figurativos (verbais e não verbais) que também explicitem a imagem do narrador e do narratário;

d) observar as inter-relações entre as linguagens verbal e não verbal, identificando o modo de sincretização do plano de conteúdo;

e) identificar as categorias correspondentes às dimensões topológica, eidética, fotológica e cromática do plano de expressão;

f) promover a homologação entre as categorias do plano de conteúdo e do plano de expressão;

g) a partir do exame das recorrências apresentadas na totalidade dos textos, depreender o éthos do enunciador e o páthos do enunciatário.

\section{Análise do corpus}

Levando em conta os procedimentos descritos anteriormente, serão aqui examinados dois anúncios da marca Dove, linha de higiene pessoal e beleza pertencente à companhia Unilever. A marca surgiu em 1957, nos Estados Unidos, vinculada a um sabonete com ingredientes hidratantes, cuja fórmula é originária de um tratamento diferente para ferimentos, utilizado pelo exército americano. Isso explica a pomba (símbolo da paz) de sua logomarca. Após essas considerações iniciais, observe-se o anúncio a seguir:

Figura 1 - Anúncio 1: Real Beleza

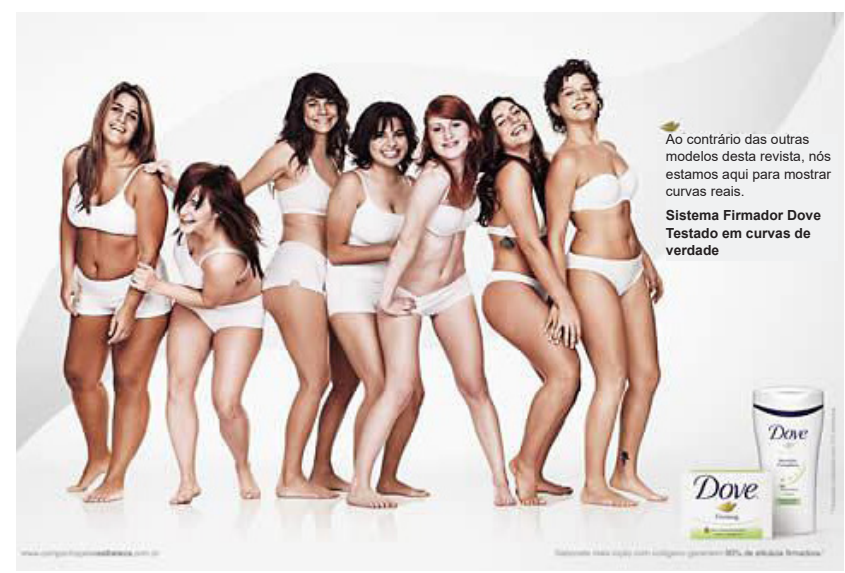

Fonte: Revista Contigo, agosto de 2005.
Pode-se perceber na Figura 1 que, em relação à instância do narrador, há no enunciado do anúncio uma projeção em 3a pessoa, dizendo: "Sistema Firmador Dove. Testado em curvas de verdade", o que, a princípio, produz um efeito de distanciamento, de objetividade. Entretanto, esse narrador delega a voz às modelos (atores do enunciado) que, em discurso direto, enunciam em $1^{\text {a }}$ pessoa: "Ao contrário das outras modelos desta revista, nós estamos aqui para mostrar curvas reais". Agora, o emprego de $1^{\mathrm{a}}$ pessoa (mesmo que do plural) acaba produzindo um efeito de subjetividade, de intimidade e, considerando que essa voz é atribuída aos interlocutores (modelos), produz-se, ainda, um efeito de realidade, pois se traz a ilusão de fala real. Além disso, no plano não verbal, tais modelos dirigem-se ao destinatário-leitor em 1 a pessoa, uma vez que o olhar e a postura corporal estão voltados a ele, como observa Barros (2012). Segundo a autora, quando atores do enunciado olham para o leitor, este é instaurado como interlocutor ( 2 a pessoa do discurso), a quem se dirige o enunciado (BARROS, 2012, p. 40). Cria-se, assim, um efeito de cumplicidade, de comprometimento. A combinação de "nós versus você" também produz efeito de informalidade. Podese ainda, nessa circunstância, cogitar a produção de um efeito de coletividade, já que o "nós" - pessoa amplificada (FIORIN, 2010) - projeta-se como sendo a voz de um grupo bastante heterogêneo de mulheres, com que o leitor (você) deve-se identificar.

Esse, aliás, é o principal intuito dos investimentos temáticos e figurativos promovidos no anúncio. Focalizando a atenção na fotografia, percebe-se que as modelos retratadas são mulheres comuns, com diferentes formas físicas, estaturas, cores, cabelos, estilos. O estilo de cada uma, inclusive, pode ser percebido por meio de suas poses: algumas se encontram em posição mais descontraída, dando a ideia de estarem divertindo-se (como a segunda, da esquerda para a direita), o que sugere uma personalidade mais extrovertida; outras apresentam postura mais ereta (como a primeira, a terceira e a sétima, da esquerda para a direita), indicando um perfil mais formal; há ainda as que se encolhem, parecendo buscar se esconder (como a que está no centro), revelando certa timidez; ou se posicionam provocantemente (como a ruiva, ao lado desta), demostrando ousadia. Ou seja, mulheres com características heterogêneas, com corpos cheios de curvas, padrão que se contrasta com o das modelos profissionais, extremamente magras e altas, a que a parte verbal do anúncio faz referência como "as outras modelos desta revista" (já que o anúncio foi veiculado em uma revista feminina). Cria-se, dessa forma, um discurso de valorização dos sujeitos que possuem as primeiras características citadas e, ao mesmo tempo, de depreciação das que possuem as últimas. 
Assim, as mulheres comuns, curvilíneas, em poses descontraídas (percebidas visualmente), bem como os elementos verbais "curvas reais" e "curvas de verdade" figurativizam os temas da realidade, do comum, do natural; em oposição às "outras modelos desta revista", as quais fazem referência à irrealidade, ao incomum, ao artificial. Ademais, as mulheres do anúncio, por serem apresentadas fotograficamente não só figurativizam a realidade, mas a iconizam. Tornam-se, assim, "copias do real" (BARROS, 2004, p. 14), produzindo um efeito, justamente, de realidade.

Quanto ao modo de sincretização do plano de conteúdo, pode-se dizer que, no anúncio da Dove, o não verbal relaciona-se de modo contratual ao verbal. Há um redimensionamento por complementação, pois a imagem das modelos amplia o sentido do verbal por meio de um efeito de realidade (apresenta uma prova visível de que as curvas são "reais", "de verdade").

No que diz respeito ao plano de expressão, nesse anúncio da Dove, a dimensão que se sobrepõe, sem dúvida, é a eidética, pois, como se observou até agora, a forma das modelos está em evidência: há visualmente uma predominância de traços curvilíneos, bem como de heterogeneidade na configuração de seus corpos; em contraposição às pressupostas características das "outras modelos desta revista". Tem-se, assim, uma homologação entre as categorias de expressão "curvilíneo versus retilíneo" e "heterogêneo versus homogêneo" e as de conteúdo "realidade versus irrealidade", "comum versus incomum" e "natural versus artificial", constituindo, assim, relações semissimbólicas.

Agora, observe-se este outro anúncio da marca Dove (Figura 2).

Figura 2 - Anúncio 2: Beleza fora da caixa

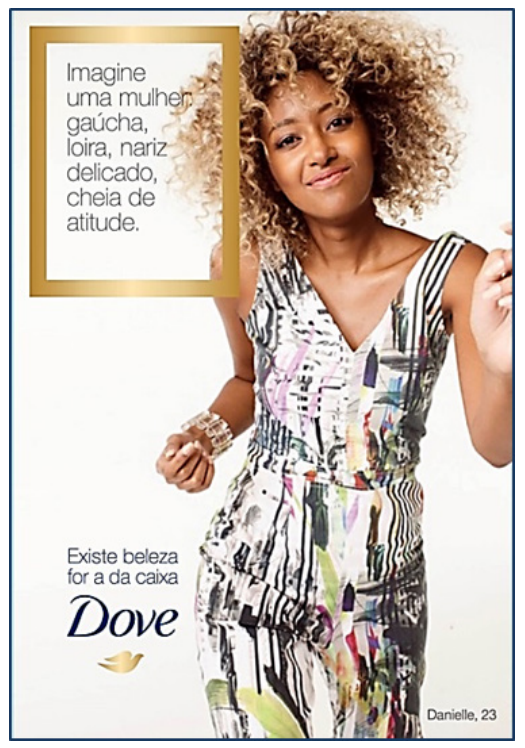

Fonte: Revista Exame, abril 2016.
No plano verbal desse anúncio, com o enunciado "Imagine uma mulher gaúcha, loira, nariz delicado, cheia de atitude", o narrador, inicialmente, projeta-se em 1a pessoa, pois trata o destinatário-leitor por "você", tratamento que fica explícito pela utilização do verbo, conjugado na 2 a pessoa do singular, do imperativo ("Imagine"). Isso se explica, porque, segundo Fiorin (2010), quando o narrador introduz no enunciado o "tu/ você", ele está projetando-se como "eu", ou seja, um "eu" que fala a um "tu/você". Também o não verbal contribui para estabelecer uma comunicação em $1 \underline{\text { a }}$ pessoa entre o ator do enunciado (a imagem que representa a pessoa da qual se fala) e o leitor. Isso ocorre por meio do olhar do ator que se dirige ao leitor, da postura do corpo, da gestualidade das mãos. Dessa forma, com o predomínio da projeção do narrador em $1^{\underline{a}}$ pessoa, tanto no verbal (narrador-leitor), como no não verbal (ator-leitor) predominam também os efeitos de subjetividade e de aproximação. No entanto, cabe observar que, no enunciado seguinte, "Existe beleza fora da caixa", a $1^{\underline{a}}$ pessoa dá lugar à $3 \stackrel{\text { a }}{ }$, anulando, de certa forma, a subjetividade que até então preponderava. Tal procedimento reflete sobre o enunciado um efeito de objetividade, conferindo a ele um tom de asseveração, endossado pela marca "Dove" que o segue, como uma assinatura. Em outras palavras, o narrador afirma e assina embaixo, agregando um efeito de credibilidade ao que diz. Aos efeitos de sentido descritos, somam-se os produzidos por outras escolhas enunciativas, como o emprego dos termos "nariz delicado" e "cheia de atitude", os quais trazem um tom afetivo ao enunciado. Criam-se, com isso, efeitos de aproximação, de acolhimento, de cumplicidade.

Em relação aos investimentos figurativos, o enunciado verbal "Imagine uma mulher gaúcha, loira, nariz delicado, cheia de atitude" conecta duas isotopias figurativas: desconectada da imagem, provavelmente, o destinatário-leitor seria levado a imaginar uma mulher loira, de pele clara; entretanto, a imagem desencadeia outro plano de leitura, apresentando uma mulata, perfeitamente adequada à descrição. Deve-se acrescentar aqui que a posição da modelo, bem como suas expressões faciais, corrobora o que é dito verbalmente pela expressão "cheia de atitude". Cria-se, assim, a ideia de uma mulher segura, forte, ousada, que valoriza seus atributos físicos e projeta-se de forma positiva socialmente. Além disso, o ator do enunciado apresenta-se figurativizado em grau máximo (iconizado), por meio de fotografia acompanhada, inclusive, de nome próprio ("Daniele") e idade ("23"), o que produz efeitos de realidade e de credibilidade. Ao se afirmar que "Existe beleza fora dacaixa", percebe-se quea "caixa"(representada tantoverbalmente, como pela borda externa ao primeiro enunciado verbal), e a imagem mental produzida inicialmente pelo leitor, figurativizam o "padrão" de beleza convencionado pela sociedade. Já a imagem da "mulata" figurativiza a 
beleza "não padrão", sendo que, no anúncio, é esta a que adquire valoração positiva, em contraposição àquela. Esse discurso ocasiona um efeito de inclusão dessas mulheres que não se enquadram nos padrões de beleza "da caixa".

No que tange ao modo de sincretização do plano de conteúdo desse anúncio, pode-se dizer que também é contratual nas duas isotopias, pois tanto a mulher de pele clara, fruto da imagem mental, quanto a mulata, revelada pela imagem fotográfica do anúncio, correspondem à descrição verbal (embora, aos olhares preconceituosos e intolerantes, seja inadmissível relacionar tal descrição à imagem de uma mulata, o que, nessa perspectiva, sugeriria o estabelecimento de uma relação polêmica entre o verbal e não verbal imaginário). Há um redimensionamento por complementação, pois a linguagem não verbal acrescenta sentidos à verbal, constituindo outro plano de leitura possível. Destaca-se, ainda, o fato de que a palavra "for a", apresenta o "a" mais distante do resto da palavra ("fora"), como se realmente estivesse "fora" da caixa, o que constitui uma contribuição do plano de expressão verbal para com o plano do conteúdo.

E, por falar em plano de expressão, o anúncio mobiliza, de modo enfático, a dimensão cromática, por meio da categoria "claro versus escuro". O elemento "claro" homologa-se ao tema do "padrão" e o elemento "escuro", ao do "não padrão", instaurando-se entre as categorias de expressão e de conteúdo uma relação semissimbólica.

Configura-se, assim, nas recorrências percebidas na totalidade do texto, um tom contestador e acolhedor; um caráter respeitador e, ao mesmo tempo, ousado, pois busca valorizar a diferença, explicitando, de forma irônica, preconceitos arraigados na sociedade. A voz da qual emana o discurso de respeito e valorização de todas as belezas constitui-se em oposição a outras vozes que não consideram belo o que se afasta do padrão (não consideram "delicado", por exemplo, o nariz de uma mulata, o qual apresenta traços característicos de sua etnia). Toma corpo, desse modo, o éthos do narrador: tolerante, inclusivo, pluralista, que promove a aceitação social da diversidade.

Observando os dados explicitados pelas análises, constata-se que os éthe do narrador e do enunciador são idênticos, no corpus selecionado, sendo construídos, em termos aristotélicos, por meio da eúnoia (benevolência), ou seja, as estratégias discursivas utilizadas centram-se no páthos. O uso de $3^{\underline{a}}$ pessoa no lugar da $1^{a}$, combinado ao emprego de 2 a pessoa no tratamento ao destinatário-leitor, por exemplo, contribui para a produção de um éthos de cumplicidade, de comprometimento com ele. A relação assimétrica entre narrador e narratário demonstra que eles são "diferentes", mas ligados por "valores comuns", uma vez que a Dove valoriza a beleza natural, não estereotipada. Desse modo, busca a identificação com o cliente, revelando um éthos de sensibilidade, de respeito às diferenças.
A cumplicidade é reforçada ainda por meio dos papéis figurativos com que se concretizam, de modo verbal e não verbal, os atores do enunciado: as mulheres comuns, a mulher acima do peso, a mulata. Dessa forma, o enunciador produz um simulacro do enunciatário que procura atingir: uma mulher que foge dos padrões de beleza convencionados. Padrões esses que se revelam, em geral, excludentes e discriminatórios. Nas palavras de Discini (2005, p. 284):

O discurso do senso comum, modalizado por um crer poder ser, um crer dever ser, um crer querer ser, segundo valores tidos como inquestionáveis, constitui bom exemplo para a cristalização de temas e figuras que fundamentam sistemas de preconceitos.

Logo, ao apresentar as figuras femininas citadas, o enunciador denuncia o preconceito e, ao mesmo tempo, propõe uma reação a ele. Afinal, as mulheres "fora do padrão" são retratadas de modo positivo: sorridentes, de bem com a vida. Não parecem crer que possam ser, nem devam ser como o modelo pré-concebido socialmente. Muito menos que o queiram ser. Constrói-se, desse modo, um páthos de elevada autoestima, de segurança, de confiança, com o qual se presume que o destinatário-leitor venha a se identificar (pois compartilha desses valores), ou de cujo modelo deseje aproximar-se. Tais escolhas enunciativas projetam um éthos de um enunciador interessado no bem estar do enunciatário, buscando sua adesão por meio da emoção. Um éthos pluralista, que valoriza positivamente a diversidade, a verdade, a liberdade, a naturalidade, e que desafia estereótipos limitados, utópicos, artificiais.

O discurso assume um tom crítico, inovador, e associa todos esses valores "incorporados" pelas imagens do enunciador e do enunciatário aos produtos anunciados. A linha de produtos Dove é apresentada, assim, como capaz de proporcionar às mulheres a "beleza real", considerando as possibilidades e a diversidade de seus corpos.

Todos esses aspectos abordados demonstram que éthos e páthos encontram-se diretamente relacionados $\mathrm{e}$ emergem da inter-relação entre o verbal e o não verbal, explicitada tanto no plano de conteúdo, como no de expressão.

\section{Considerações finais}

Como foi possível verificar, os preceitos teóricos da semiótica greimasiana podem contribuir imensamente para a depreensão do éthos do enunciador e do páthos do enunciatário de textos sincréticos, como os publicitários. Afinal, tal teoria dedica-se ao exame de qualquer texto, manifestado por qualquer plano de expressão e busca explicar não só o que o texto diz, mas como diz. 
Assim, a identificação das recorrentes marcas (verbais e não verbais) da enunciação, manifestadas por meio das projeções do enunciador como narrador e do enunciatário como narratário, dos efeitos de sentido de tais projeções, dos investimentos temáticos e figurativos, das formas de interação entre o verbal e o não verbal (no plano de conteúdo e no plano de expressão) pode constituir um percurso de análise bastante produtivo no que se refere à explicitação, de forma mais sistemática e menos intuitiva, do ethos e do páthos. Tal explicitação, no caso específico da análise dos anúncios da Dove, também propicia o debate acerca dos padrões de beleza femininos, auxiliando a luta pelo respeito às diferenças de qualquer natureza. Afinal, para se combater o preconceito é necessário, primeiramente, reconhecê-lo, mesmo que recôndito nas profundezas da língua.

Acrescente-se, por fim, que as imagens discursivas projetadas nos anúncios ora abordados propiciam aproximação com o perfil de público que neles se representa, ou seja, a mulher comum, a mulher com imperfeições, que se identifica com tal discurso porque nele se vê projetada. Posto que a maioria da população feminina se encaixa nesse perfil, essa é, sem dúvida, uma boa estratégia para impulsionar a adesão aos produtos da marca.

\section{Referências}

ARISTÓTELES. Retórica. Lisboa: Imprensa Nacional-Casa da Moeda, 2008.

BARROS, Diana Luz Pessoa de. Teoria semiótica do texto. São Paulo: Ática, 1997.

BARROS, Diana Luz Pessoa de. Interação em anúncios publicitários. In: PRETI, Dino (org.). Interação na fala e na escrita. São Paulo: Humanitas, 2002. p. 17-44.

BARROS, Diana Luz Pessoa de. Figurativização e publicidade. Alfa, São Paulo, v. 48, n. 2, p. 11-31, 2004.

BARROS, Diana Luz Pessoa de. Algumas reflexões semióticas sobre a enunciação. In: DI FANTI. Maria da Gloria; BARBISAN, Leci Borges. (org.). Enunciação e discurso. São Paulo: Contexto, 2012. v. 1, p. 25-49.

BENVENISTE, Émile. Problemas de Linguística Geral I. 4. ed. Campinas: Pontes, 1995.

CONTIGO. São Paulo: Editora Abril, ago. 2005.

DISCINI, Norma. A comunicação nos textos. São Paulo: Contexto, 2005.

EXAME. São Paulo: Editora Abril, abr. 2016.

FIORIN, José Luiz. As astúcias da enunciação: as categorias de pessoa, espaço e tempo. 2. ed. São Paulo: Ática, 2010. https://doi.org/10.11606/issn.2176-9419. v0i2p227-231
FIORIN, José Luiz. As relações entre enunciador e enunciatário. In: TOLDO, Claudia; STURM, Luciane. Enunciação e produção de sentidos: o texto em questão uma homenagem ao Prof. José Gaston Hilgert. Campinas, SP: Pontes Editores, 2016. p. 51-68.

FIORIN, José Luiz. Por uma definição das linguagens sincréticas. In: OLIVEIRA, Ana Cláudia de; TEIXEIRA, Lucia. Linguagens na comunicação: desenvolvimentos de semiótica sincrética. São Paulo: Estação das Letras e Cores, 2009. p. 15-40. https://doi.org/10.21709/casa.v12i2.7565

GOMES, Regina Souza. O sincretismo no jornal. In: OLIVEIRA, Ana Cláudia de; TEIXEIRA, Lucia (org.). Linguagens na comunicação: desenvolvimentos de semiótica sincrética. São Paulo: Estação das Letras e Cores, 2009. p. 215-245. https://doi.org/10.21709/casa.v12i2.7565

GREIMAS, Algirdas Julien. Semiótica figurativa e semiótica plástica. Tradução de Assis Silva. In: OLIVEIRA, Ana Cláudia de (org.). Semiótica plástica. São Paulo: Hacker Editores, 2004. p. 75-96.

GREIMAS, Algirdas Julien; COURTÉS, Joseph. Dicionário de Semiótica. São Paulo: Contexto, 2013. https://doi. org/10.11606/issn.2316-7114.sig.1984.90477

MAINGUENEAU, Dominique. A propósito do ethos. In: MOTTA, Ana Raquel; SALGADO, Luciana (org.). Ethos discursivo. São Paulo: Contexto, 2008. p. 11-29.

MAINGUENEAU, Dominique. Ethos, cenografia, incorporação. In: AMOSSY, Ruth (org.). Imagens de si no discurso: a construção do ethos. São Paulo: Contexto, 2013. p. 69-92.

MONTEIRO, Ricardo de Castro. As muitas vozes da canção: uma análise de Yesterday. In: LOPES, Ivan Carlos; HERNANDES, Nilton (org.). Semiótica: objetos e práticas. São Paulo: Contexto, 2005. p. 43-59.

TEIXEIRA, Lucia. Entre dispersão e acúmulo: para uma metodologia de análise de textos sincréticos. Gragoatá, Niterói, v. 16, p. 209-227, jan./jul. 2004.

Recebido em: 31/5/2018.

Aprovado em: 28/6/2019.

Publicado em: 30/11/2019.

Autoras:

ROSEMÉRI LORENZ

Doutoranda em Letras na Universidade de Passo Fundo e professora da área de Letras na mesma universidade.

Orcid: http://orcid.org/0000-0001-9432-5524

E-mail: lorenz@upf.br

Luciana Maria Crestani

Doutora em Letras pela Universidade Presbiteriana Mackenzie, professora no Curso de Letras e no Programa de Pós-Graduação em Letras da Universidade de Passo Fundo.

Orcid: http://orcid_org/0000-0003-1265-7803

E-mail: lucianacrestani@upf.br

Endereço: Av. Brasil Leste, 285 - São José

99052-900, Passo Fundo, RS, Brasil 